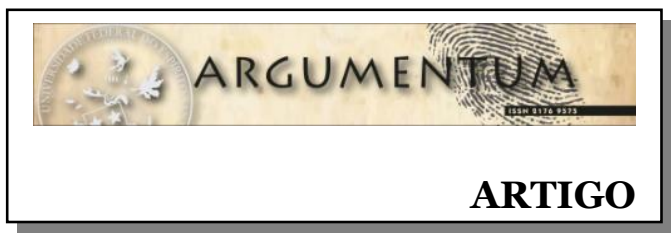

\title{
Direito e violência: um estudo sobre o pensamento de Walter Benjamin
}

\author{
Law and violence: a study of Walter Benjamin's thinking
}

\author{
Oneide PERIUS* \\ https://orcid.org/o000-0002-0298-9727
}

\begin{abstract}
Resumo: O artigo propõe uma análise das condições de possibilidade da crítica da violência nas sociedades contemporâneas. Utiliza-se, para alcançar esse objetivo, da filosofia do jovem Walter Benjamin. Dois aspectos serão especialmente destacados. O primeiro refere-se à necessidade de ir além das críticas feitas pelos pacifistas, em direção a uma crítica da estrutura social e jurídica. O segundo aspecto a ser destacado, é que a Gewalt - termo benjaminiano que designa, ao mesmo tempo, violência e poder - nunca é totalmente absorvida para o interior de uma determinada ordem. As condições de possibilidade de uma destituição da ordem existente estão, portanto, contidas na dinâmica dialética desse conceito.
\end{abstract}

Palavras-Chave: Violência. Poder. Direito. Crítica. Walter Benjamin.

Abstract: The article proposes an analysis of the conditions for the possibility of criticizing violence in contemporary societies. To achieve this objective, the philosophy of the young Walter Benjamin is used. Two aspects will be especially highlighted. The first refers to the need to go beyond the criticisms made by pacifists, towards a critique of the social and legal structure. The second aspect to be highlighted is that Gewalt - a Benjaminian term that signifies violence and power simultaneously - is never fully absorbed into a given order. The conditions for the possibility of the destitution of the existing order are, therefore, contained in the dialectical dynamics of this concept.

Keywords: Violence. Power. Law. Critique. Walter Benjamin.

Submetido em: 29/6/2020. Revisado em: 21/9/2020. Aceito em: 19/10/2020.

A crítica da violência é, em nossos dias, uma das tarefas mais urgentes e necessárias. Estamos imersos em uma realidade na qual esse fenômeno se multiplica diariamente e tem um impacto concreto na vida cotidiana e nos processos de subjetivação. Ainda que sua presença em nossa época não constitua, propriamente, uma novidade, seus efeitos são ampliados pela exploração midiática e sua consequente espetacularização. Isto é, uma vasta rede de produtos se alimenta deste cenário de devastação, e nos faz perceber como estamos distantes de estratégias efetivas de enfrentamento do problema. Em razão disso, existe o risco de o caráter explícito e imediato da violência cotidiana nos fazer desconsiderar e julgar desnecessária uma reflexão um pouco mais aprofundada sobre o que se denomina, propriamente, violência. Em outras palavras, para não nos atermos exclusivamente ao

\footnotetext{
* Filósofo. Doutor em Filosofia. Professor de Filosofia da Universidade Federal do Tocantins (UFT, Palmas, Brasil). Quadra 109 Norte, Avenida NS-15, ALCNO-14 Plano Diretor Norte, CEP.: 77001-090, Palmas (TO). E-mail: oneideperius@uft.edu.br.

(C) A(s) Autora(s)/O(s) Autor(es). 2019 Acesso Aberto Esta obra está licenciada sob os termos da Licença Creative Commons Atribuição 4.o Internacional (https://creativecommons.org/licenses/by/4.o/deed.pt_BR), que permite copiar e redistribuir o material em qualquer suporte ou formato, bem como adaptar, transformar e criar a partir deste material para qualquer fim, (cc) $\mathrm{Br}$ mesmo que comercial. O licenciante não pode revogar estes direitos desde que você respeite os termos da licença.
} 
conjunto de soluções pontuais para o problema, precisamos expor e compreender as raízes da violência que estão entranhadas em nossa cultura.

Nesse contexto, o direito se apresenta como um âmbito que pode apresentar soluções eficazes. Cada vez mais vem sendo naturalizada a ideia de que a violência contra a mulher, por exemplo, tem de ser combatida exclusivamente por uma legislação que a criminalize. E assim, pontualmente, uma vasta gama de problemas sociais encontra no direito o suposto mecanismo de neutralização da violência. Essa percepção torna-se cada vez mais forte a ponto de observarmos uma crescente juridificação das relações sociais em suas manifestações mais elementares. Uma vez instituída uma ampla rede de códigos jurídicos que sejam capazes de prever os mínimos aspectos da vida cotidiana, resta o poder de polícia, como braço forte do Estado, com a finalidade de resolver o que extrapola o âmbito jurídico, bem como de garantir a força que as normas precisam para se impor.

O que é preciso trazer para a discussão, no entanto, quando se leva a sério a tarefa de uma crítica da violência, é outra questão fundamental que, muitas vezes, permanece encoberta. O direito, enquanto mecanismo de proteção de determinada ordem social ordem esta que, no limite, utiliza de violência explícita para se manter - é, também, resultado de uma ação violenta que o institui e depende, por sua vez, da força e da violência para se manter. Assim, para dizê-lo de outro modo, a sensação de proximidade da violência cotidiana pode nos fazer perder de vista, precisamente, o caráter violento da própria ordem instituída da qual o direito é apenas um mecanismo de sustentação.

Neste sentido, a discussão que se pretende conduzir neste artigo, assumindo como perspectiva teórica a filosofia benjaminiana, expressa especialmente no artigo Zur Kritik der Gewalt (Para uma crítica da Violência), situa-se no coração do debate contemporâneo em torno da biopolítica. Ou seja, até que ponto essa filosofia pode nos ajudar a compreender a extensão e a dinâmica do biopoder nas sociedades contemporâneas e fazer a sua crítica? Além disso, como essa análise da Gewalt (poder, violência) pode permitir o acesso a uma esfera de manifestação da potência que escape desse âmbito da vida controlada? Ou seja, a leitura benjaminiana revela a dinâmica do poder violento que está entranhado na estrutura social, que controla a vida e impõe modelos de subjetivação, mas também revela uma potência que nunca pode ser plenamente dominada ou instrumentalizada. Não basta, portanto, uma análise do poder e da violência sobre a vida. Essa deverá vir acompanhada, necessariamente, de uma análise da força e da potência da vida.

Partindo do contexto que foi esboçado, o artigo traz como proposta de estudo a análise da relação entre dois conceitos muito caros e importantes na obra do filósofo de Berlim: direito e violência. Por mais que a relação entre esses conceitos esteja presente em muitos momentos de sua obra, o núcleo dessa imbricação é cuidadosamente analisado no famoso artigo de 1921, intitulado Zur Kritik der Gewalt. Desse modo, pretende-se partir da reconstrução do argumento benjaminiano, tendo como objetivo de fundo não uma mera exegese de um texto historicamente importante, mas, para além disso, lançar luz sobre o presente em que esse profundo entrelaçamento entre 
direito e violência permanece encoberto, o que leva ao entendimento do fenômeno da crescente juridificação das relações sociais como sendo mera consequência do progresso das sociedades ocidentais.

A narrativa predominante, no que se refere à relação entre direito e violência, é aquela que mostra o direito como um instrumento racional que ajuda a solucionar conflitos de uma forma não violenta. Portanto, de alguma maneira, direito e violência foram sempre apresentados, ao menos na tradição da filosofia moderna, como sendo conceitos inversamente proporcionais, isto é, quanto mais efetivo é um código normativo tanto menos violência poderá ser observada em determinada sociedade. É, portanto, do questionamento dessa concepção, que de tão naturalizada se tornou uma espécie de senso comum, que se iniciam as considerações benjaminianas que pretendemos abordar em nosso artigo. A hipótese de fundo que guia nossa leitura é a de que a tarefa de uma crítica da violência não pode, de maneira alguma, se furtar ao esforço de empreender, também, uma crítica do direito.

\section{A filosofia benjaminiana: panorama geral}

Por mais difícil que seja alcançar uma posição de conjunto para, desde esse ponto, avaliar melhor cada um dos elementos, dos conceitos e dos escritos de um filósofo como Walter Benjamin, tanto mais isso se revela um exercício necessário. Não se trata, obviamente, de preencher as lacunas interpretativas com perspectivas de leitura impostas a qualquer um de seus textos. A visão de conjunto, no caso da obra do filósofo berlinense, é necessária para perceber o movimento geral, o caminho e a direção que, teimosamente, esta obra persegue. O movimento dialético de perceber o todo em cada um dos mínimos elementos da realidade e, ao mesmo tempo, iluminar qualquer uma das pequenas partes, dos restos e das ruínas, desde uma perspectiva de conjunto, vai ganhando corpo na sua obra. No entanto, é importante destacar, a característica própria desse movimento dialético, no caso benjaminiano, é a de mostrar a inadequação desses fragmentos da realidade em relação à narrativa que pretendia ter-lhes definido um lugar. Este duplo movimento é absolutamente característico e, portanto, se impõe ao aguçado e atento exercício filosófico. Não se trata, assim, de uma dialética que procura o caminho da compreensão total do movimento da realidade. Isso porque, para um filósofo como Walter Benjamin, não há nenhum segredo oculto que possa subitamente revelar o que a realidade é propriamente. Há, sim, restos que permaneceram em segredo por nunca terem sido suficientemente valorizados para que uma determinada visão de conjunto, uma determinada totalidade, pudesse seguir se impondo.

A dialética benjaminiana é uma dialética impertinente, que expõe as lacunas da totalidade a partir dos elementos que ficaram de fora dela ou que foram violentamente excluídos da narrativa da totalidade perfeita. Assim, ao mesmo tempo, é uma dialética do pequeno, do feio, do descartado. A potência de desagregação contida em cada um desses elementos é o seu combustível. Desse modo, não é uma dialética que promete uma explicação da História Universal. Trata-se de descobrir a história do que se perdeu, do que foi abandonado, dos que foram mortos e permanecem ainda insepultos, dos que não têm lugar. Tudo isso conduz a um trabalho gigantesco que lembra o labor

Argum., Vitória, v. 12, n. 3, p. 58-68, set./dez. 2020. | ISSN 2176-9575 
de um detetive. O objetivo maior disso é mostrar o relato da História Universal como sendo um ato de violência, tendo em vista que uma ampla gama de acontecimentos e personagens nele está ausente.

Todos esses pequenos elementos da realidade que permanecem fora dos relatos oficiais e supostamente universais não são, no entanto, somente elementos quantitativos. Não se trata apenas de torná-los visíveis para que o relato universalmente aceito seja mais completo. O que ocorre quando o filósofo se atenta detalhadamente a tais elementos é a descoberta de que o relato oficial, aquilo que se denomina História com $\mathrm{H}$ maiúsculo, não é só incompleto, mas falso. A coerência deste relato oficial depende de que esses inúmeros aspectos obliterados permaneçam soterrados. A exigência que emana daquilo que foi retirado dos livros da História, daquilo que permanece soterrado é, assim, a destruição do relato propriamente dito. (LÖWY, 2005). Como destaca o filósofo: "Em cada época, é preciso arrancar a tradição ao conformismo, que quer apoderar-se dela. [...] O dom de despertar no passado as centelhas da esperança é privilégio exclusivo do historiador convencido de que também os mortos não estarão em segurança se o inimigo vencer" (BENJAMIN, 1994, p. 224-225; 1991a, p. 695). Outra narrativa baseada em outra temporalidade, que não mais a temporalidade linear pressuposta nos relatos do progresso histórico, precisa se mostrar. Essa é a realidade desde a qual a filosofia benjaminiana vai se constituindo.

Os grandes pensadores não são aqueles que detêm a solução de todos os enigmas em suas cabeças. Pelo contrário, a maioria dos que se apresentam dessa maneira não passam de charlatões. Os grandes pensadores são aqueles para os quais a realidade nunca perde o caráter enigmático e, portanto, fazem da cuidadosa investigação sua vocação e sua tarefa.

Quanto ao texto que servirá de base para o presente estudo, Zur Kritik der Gewalt, é preciso partir, inicialmente, de uma análise do título. O conceito de crítica, que aparece no início, já conhece um longo desdobramento na história da filosofia. Depois de Kant, que levou esse conceito ao centro de sua filosofia, certamente o mesmo não pode ser utilizado de forma impensada. A crítica kantiana pretende ser a abordagem em que se mostram os limites e as condições de possibilidade dos conceitos. Fazer a crítica do fenômeno da violência em suas múltiplas manifestações é, assim, antes de qualquer coisa, um exigente trabalho de análise. Um trabalho em que se pretende acompanhar a constituição do campo semântico deste polissêmico e ambíguo termo Gewalt (poder, violência, potência). Ou seja, Benjamin, obviamente, não está aderindo simplesmente ao movimento de uma recusa pacifista da violência, bastante em voga nos anos que antecederam o escrito, pelas circunstâncias da guerra. O próprio filósofo ressalta essa questão quando fala da crítica da violência: "[...] sua crítica realmente eficaz não é tão simples como querem os pacifistas e ativistas" (BENJAMIN, 1986, p. 165; 1991b, p. 187). O objetivo do texto, como pretendemos demonstrar, é outro.

Em uma perspectiva mais geral, podemos observar que a preocupação mais evidente e manifesta de toda a filosofia benjaminiana é aquela de captar os meios e as possibilidades de interromper o movimento da história como tal. A história é, hegemonicamente, a narrativa dos que venceram. No entanto, a narrativa baseada no 
poder e na força, tendo os Estados - esses entes metafísicos - como protagonistas, havia demonstrado claramente para onde conduzia: à guerra, ao culto ao militarismo, ao Estado forte e policial. Todo esse aparato do poder, instituído e enraizado em múltiplos aspectos da vida social, revela claramente um culto à violência e ao poder enquanto controle absoluto sobre a vida. Dessa forma, não apenas a narrativa de legitimação deste estado de coisas precisa ser desmentido. Além disso, faz-se necessário mostrar quais as brechas ou frestas dessa monumental construção podem levá-la à implosão. Nesse sentido, parece que já desde os escritos juvenis, Benjamin está ocupado em mapear toda a potência (Gewalt) que permanece fora dessa ordem e da lógica de sua manutenção. No âmbito da linguagem, por exemplo, mostrando a insuficiência da concepção burguesa, onde a linguagem era reduzida a mero instrumento de comunicação, o filósofo busca, nessa mesma linguagem, uma potência de constituição e criação das coisas. No âmbito do escrito sobre a violência, por sua vez, preocupa-se em mostrar que nem toda potência ou violência é capturada para o interior de uma ordem instituída. Nesse sentido, é possível fazer a crítica, ou seja, mostrar as condições de possibilidade de um movimento revolucionário, um movimento que consiga interromper a estabilidade violenta da ordem instituída.

Outro aspecto, portanto, que merece destaque, ainda nestas considerações de caráter mais geral sobre a filosofia de Walter Benjamin, é o cuidado com que o filósofo vai distinguindo diferentes níveis de análise da violência. Não se trata exclusivamente, como já foi apontado, de considerar como sendo violência aquilo que uma determinada ordem social define como tal. Um panorama mais geral de análise e crítica nos leva à consideração de que a própria ordem como tal e os mecanismos de que se utiliza para a sua manutenção são, em si mesmos, profundamente violentos. $\mathrm{O}$ conceito de uma totalidade falsa - conceito este que será muito caro aos pensadores da teoria crítica da chamada Escola de Frankfurt - é, dessa forma, ensaiado já nestes escritos do jovem Benjamin.

\section{A imbricação entre Direito e Violência}

O texto benjaminiano não propõe uma crítica da violência enquanto fenômeno abstrato ou mesmo enquanto conceito abstrato. Exatamente por isso revela-se insuficiente a defesa de princípios abstratos como estratégias de enfrentamento à violência. Por exemplo, utilizar o princípio da inviolabilidade do indivíduo, garantido juridicamente, como ocorre na filosofia liberal moderna. Isto é, fazer uma crítica da violência com os critérios que as sociedades liberais nos fornecem não está à altura da exigência de uma crítica da violência enquanto tal. Este exercício seria muito mais uma crítica daquilo que as sociedades liberais definiram como sendo a violência. Perder-seia, assim, uma perspectiva mais geral que pudesse dar conta de uma crítica dessas sociedades e da ordem social por elas instituída.

Nestas sociedades, o direito apresenta-se como o caminho e o destino natural para os indivíduos. Apresenta-se, em outras palavras, como o meio adequado e necessário para garantir ao indivíduo a segurança ante as ameaças que se tornariam generalizadas se $o$ poder permanecesse em suas mãos, sem nenhuma mediação. A narrativa é a de que monopolizar o poder e a violência é a única forma de salvar os indivíduos. Hobbes,

Argum., Vitória, v. 12, n. 3, p. 58-68, set./dez. 2020. | ISSN 2176-9575 
nesse sentido, pode ser realmente considerado o fundador dessa perspectiva moderna de pensar a política e o direito. Nas palavras de Walter Benjamin: “[...] o poder - que o direito atual procura retirar do indivíduo em todas as áreas de atuação - se manifesta realmente como ameaça" (BENJAMIN, 1986, p. 163; 1991b, p. 183). Ou seja, o ponto de partida de toda a filosofia política moderna de caráter liberal é o indivíduo e este, por sua vez, só existe enquanto conceito angular cuja realidade se dá no âmbito das estruturas sociais existentes às quais se adapta. Tanto o direito liberal quanto o conceito moderno de indivíduo, desse modo, por serem produtos das sociedades liberais, não nos fornecem pontos de partida suficientes para empreender uma crítica da violência. As palavras do filósofo de Berlim são bastante pontuais no que se refere à exigência que se impõe à crítica: "Sua impotência é total quando não questiona o próprio corpo da ordem jurídica, mas apenas leis ou costumes jurídicos isolados, que então serão protegidos pelo direito com o seu poder" (BENJAMIN, 1986, p. 165; 1991b, p. 187).

Em relação aos conceitos e às instituições que surgem no âmbito da defesa de uma determinada ordem, é preciso remetê-las, também, ao conjunto social que lhes investe de sentido. Assim, outro ponto extremamente importante que Walter Benjamin destaca nesse texto é em relação ao alvo costumeiro da crítica da violência. Depois da guerra ainda ressoa com muita força a crítica pacifista ao militarismo. Por maior que seja, no entanto, a legitimidade desse tipo de crítica, muito tímida é sua efetividade. Por que isto se dá? Exatamente pelo fato de o militarismo não ser uma estrutura abstrata que subsista de forma autônoma. Se assim fosse, estaria completamente legitimada uma crítica isolada endereçada a essa estrutura. A questão, porém, não é essa. Um complexo conjunto de instituições - o Estado, o direito, a polícia, etc. compõem um status quo no qual o militarismo encontra sua legitimação. Isto é, o militarismo não é um fim em si mesmo, ou pelo menos não se apresenta como tal. É, ao invés disso, o braço mais visível, em alguns momentos, de um corpo do qual emana sua força. A crítica da violência, dessa maneira, não pode se satisfazer em um movimento de crítica de um ou outro fenômeno no qual essa dinâmica própria desemboca. Isso conduziria a uma perda de foco, pois não nos levaria a uma real compreensão da lógica imanente desses fenômenos, mas apenas tocaria um ponto abstrato apartado da dinâmica da totalidade.

Outro exemplo é a crítica ao poder de polícia. Dá-se algo muito parecido também com este fenômeno. $\mathrm{O}$ poder de polícia ou, então, a violência policial, estão ancorados em uma fonte de onde se origina sua legitimidade e da qual são meios para fins previamente estabelecidos.

\footnotetext{
Na verdade, o 'direito' da polícia é o ponto em que o Estado - ou por impotência ou devido às inter-relações imanentes a qualquer ordem judiciária - não pode mais garantir, através da ordem jurídica, seus fins empíricos, que deseja atingir a qualquer preço. Por isso, 'por questões de segurança', a polícia intervém em inúmeros casos, em que não existe situação jurídica definida, sem falar dos casos em que a polícia acompanha ou simplesmente controla o cidadão, sem qualquer referência a fins jurídicos, como um aborrecimento brutal, ao longo de uma vida regulamentada por decretos (BENJAMIN, 1986, p. 166; 1991b, p. 189).
} 
É bom salientar, no entanto, que nenhum tipo de ativismo é criticado por Benjamin. Em nenhum momento o filósofo berlinense relativiza ações que venham a enfrentar focos específicos deste poder/violência em questão. $\mathrm{O}$ enfrentamento organizado da violência policial ou a crítica pacifista do militarismo, por exemplo, não merecem nenhum tipo de reprovação por parte do filósofo. Muito pelo contrário, bem sabe Benjamin que toda violência e todo poder, no momento em que se põem, encontram diante de si algo que lhes resiste. A direção da crítica que o filósofo pretende assumir é outra. Isto é, pretende identificar a fonte originária da violência da qual esses fenômenos citados são apenas a manifestação mais visível.

Após termos demonstrado que a direção da crítica benjaminiana não se restringe às faces mais visíveis da violência nas sociedades modernas, mas se dirige à própria constituição desta ordem social, é hora de identificar o argumento central no que se refere aos conceitos de direito e violência.

Logo no início do texto, Walter Benjamin destaca: "[...] qualquer que seja o efeito de uma determinada causa, ela só se transforma em violência, no sentido forte da palavra, quando interfere em relações éticas." (BENJAMIN, 1986, p. 16o; 1991b, p. 179). Ou seja, o texto benjaminiano se ocupará de uma análise da violência que marca as relações humanas e que, como tal, é parte dessas relações. Não será o caso de, em nenhum momento, buscar uma fonte natural ou uma explicação de ordem ontológica sobre o ser do que se entende por violência. E é exatamente por este motivo que o direito, em seu papel de mediar as relações humanas, torna-se imediatamente o foco de análise para o filósofo.

Ao longo da história, o direito sempre foi entendido como sendo o espaço de articulação e definição de normas que orientam o agir humano. O direito, assim, assume o papel de codificar aquilo que os seres humanos entendem como sendo correto ou, então, aquilo que entendem como sendo justo. No âmbito da tradição do que se entendia como direito natural, a busca era a de reescrever em linguagem humana as regras que supostamente a natureza havia garantido e eternizado. $\mathrm{Na}$ tradição do chamado direito positivo, as coisas se dão de outra forma, isto é, o direito, entendido como produto da convenção humana, é o código do que é correto e justo que as sociedades estabelecem para si mesmas. Em ambos os casos o direito é o meio ora natural, ora social - que tem como tarefa garantir a ordem daquilo que é entendido como correto e como justo.

Olhando com maior proximidade, porém, percebe-se que a fonte legitimadora que institui o direito está, em ambos os casos, fora do próprio direito: os grupos autorizados a interpretar o que é a natureza e o que ela nos prescreve, no caso do direito natural; as forças sociais capazes de impor suas ideias, no caso do direito positivo. Ou seja, a força ou potência que é capaz de por ou depor um determinado código de normas nunca se esgota totalmente no âmbito deste mesmo código. $\mathrm{O}$ campo semântico próprio do termo Gewalt pode ser estabelecido partindo do direito enquanto potência e mesmo violência que normatiza e tem como tarefa normalizar determinadas formas de vida, mas não pode permanecer nisso. Um determinado 
código de leis sempre pode ser destituído ou modificado. E isso se dá justamente pelo fato de a potência nunca se esgotar totalmente em qualquer código que seja.

É interessante observar, assim, que toda ordem social, mantida enquanto ordem pelo direito, é uma ordem possível dentre inúmeras outras. Isso significa que, para se afirmar enquanto ordem legítima, processos bastante violentos, tais como guerras, revoluções, conflitos, coerções ou imposições, tiveram lugar em algum momento da história. Na origem do direito não está um fundamento racional inquestionável que poderia ter se afirmado por si mesmo. Na origem está, isso sim, o conflito. O direito nasce de um ato de violência, se mantém pela força e pela violência até que outra ordem mais potente consiga suplantá-lo.

Dessa forma, se desfaz logo de início a ilusão de que o direito é a manifestação mais plena de uma racionalidade avessa à violência. Fica estabelecido, por outro lado, que a própria racionalidade vai sendo constituída por uma história enraizada na violência. Isto é, a história nos mostra que para uma determinada ideia ser aceita, ela depende muito mais de uma violenta imposição do que de um diálogo não-violento. No entanto, esta crítica que rompe com a possibilidade de estabelecer limites claros entre direito e violência não é ainda, fundamentalmente, o núcleo da crítica benjaminiana. $\mathrm{O}$ autor pretende nos conduzir, partindo desse esclarecimento, até uma observação mais específica da dinâmica própria do direito e de como certa forma de violência está nele enraizada. E, nesse sentido, chama atenção a afirmação que encontramos já nas primeiras páginas de seu artigo: "A lei se mostra ameaçadora como o destino." (BENJAMIN, 1986, p. 165; 1991b, p. 188).

A ameaça do destino, como sabemos, é um elemento próprio do mundo mítico. Isto é, no mito a lei implacável é o destino. Nada podiam fazer contra isso os pobres mortais. $\mathrm{O}$ jogo de forças é totalmente desproporcional. As violentas forças que fazem girar a roda do destino não poupam a vida dos que pretendem resistir. Dessa maneira, no mito, a vida é despojada de qualquer indício de potência, pois todo o poder se concentra fora da vida humana e atua constantemente sobre ela. Os heróis da tragédia grega são, talvez, os primeiros que ensaiam uma rebelião contra isso, contra o implacável destino. Por mais que esse destino se imponha e por mais que o herói da tragédia, tentando fugir, se enrede em sua teia, ainda assim toda sua existência testemunha a busca de forças para lutar contra a ordem imposta pelo destino. A tragédia grega, desse modo, ao mesmo tempo em que participa do mundo do mito, anuncia a sua dissolução (CHAVES, 1994).

No entanto, qual o significado exato da frase que traça um paralelo entre a lei e o destino? Os leitores e estudiosos da chamada "teoria crítica" estarão amplamente familiarizados com o que se denomina "dialética do esclarecimento". Antes de ser o título de uma das mais importantes obras da filosofia no século $\mathrm{XX}$, essa expressão aponta para um amplo movimento teórico que pretende evidenciar os elementos regressivos - míticos - de nossa racionalidade esclarecida, bem como destacar os elementos de racionalidade esclarecida que já estariam presentes no mito. Ou seja, a tarefa de desmitologizar o pensamento e a racionalidade seria constante, presente, inclusive nos relatos míticos. Dessa forma, visto desde essa perspectiva, o texto de

Argum., Vitória, v. 12, n. 3, p. 58-68, set./dez. 2020. | ISSN 2176-9575 
Walter Benjamin pode ser lido como um dos escritos precursores, no âmbito da teoria crítica, deste exercício teórico. $\mathrm{O}$ argumento que vai sendo apresentado pelo filósofo, portanto, é o de que assim como a lei do destino, no mundo mítico, já trazia em si a potencialidade de sua própria dissolução, também o direito contemporâneo regride à mitologia quando a lei se equipara com o destino no mundo do mito.

Como, entretanto, isso é possível? O mundo do mito torna absoluta, sob o signo do destino, uma ordem natural cujo poder determinante sobre a vida é gigantesco. Nenhum modo de vida pode fugir dessa lei sem que se façam perceber as consequências dessa transgressão. No mundo do direito, nas sociedades contemporâneas, curiosamente, vemos a mesma dinâmica se afirmar com uma força implacável. O que qualifica a vida nessas sociedades é a obediência e o respeito à lei, ainda que não se entenda o seu sentido. Tal como na parábola Diante da Lei, de Kafka (2003, p. 198-200), os aspectos mais visíveis da lei são seu caráter inacessível e, ao mesmo tempo, ameaçador. A vida, assim, sob a égide do direito, vai sendo esvaziada de sua potência e sendo reduzida à mera vida (bloßen Lebens).

É preciso ressaltar, contudo, que Walter Benjamin não está, dessa maneira, fazendo uma apologia da transgressão das leis. A analítica benjaminiana vai sendo conduzida no sentido de mostrar a potência homogeneizadora do direito e o caráter preponderantemente autoritário e violento da ordem instituída. Dessa maneira, toda força e violência que essa totalidade social mobiliza para se instituir e para se manter é denominada violência mítica. Mítica, pois é uma violência que é mero instrumento para a manutenção de uma ordem inquestionável. E a função do mito é exatamente essa: tornar impenetrável e estática uma determinada ordem posta. No mito, cada acontecimento corrobora esta ordem. O direito, por sua vez, vai também se constituindo como poder de vida e de morte. Todo o aparato estatal investe de uma força descomunal essa ordem à qual os indivíduos precisam se submeter. Em outras palavras, estamos próximos do mundo do mito e submetidos à violência mítica, pois a liberdade de constituição de formas de vida está restrita aos modos aceitos e recomendados. Toda hybris, enquanto excesso ou transgressão, tal como no mundo do mito, será castigada.

A crítica da violência, assim, precisa se tornar uma crítica da própria racionalidade. A forma como as sociedades são organizadas e como a vida humana é controlada no interior delas constitui uma longa história de violência que a racionalidade não pode reprimir. Olhar para o horror e para a morte que resultaram e resultam das políticas de controle da vida é um gesto necessário e urgente.

No entanto, haveria alguma forma de poder/violência fora desse círculo instituído da violência mítica? Walter Benjamin responderia esta pergunta de forma afirmativa. $\mathrm{O}$ autor explora, para isso, o enigmático conceito de violência pura ou violência divina (göttliche reine Gewalt). E explica esse conceito da seguinte maneira:

Deus se opõe ao mito, assim também opõe-se ao poder mítico o poder divino. Este é o contrário daquele, sob todos os aspectos. Se o poder mítico é instituinte do direito, o poder divino é destruidor do direito; se aquele estabelece limites, este rebenta todos os limites; se o poder mítico é ao mesmo 
tempo autor da culpa e da penitência, o poder divino absolve a culpa(BENJAMIN, 1986, p. 173; 1991b, p. 199).

Deus se opõe ao mito, pois nunca desvendamos completamente seus desígnios. Isto é, Deus nunca se esgota numa imagem que dele fizermos. Assim como, também, nenhum poder instituído, por mais que utilize de justificativas teológicas, consegue capturar para o interior do seu círculo mítico a vontade de Deus. Em Deus se manifesta, dessa forma, uma potência de dissolução de qualquer ordem baseada na violência mítica. A pura violência divina, assim, nunca se presta como meio para qualquer outro fim fora de si mesma. Não é uma violência que possa ser instrumentalizada. É, em outras palavras, a busca permanente de justiça. Mas não a noção de justiça expressa por nossos códigos jurídicos. Pelo contrário, trata-se da justiça inominável, cuja busca nunca se esgota. Revela-se, dessa maneira, como uma força inesgotável que impulsiona os seres humanos, por mais oprimidos e debilitados que estejam, a nunca se conformar completamente no interior de uma estrutura violenta.

\section{Considerações Finais}

As discussões contemporâneas em torno da biopolítica desdobram, em grande parte, o conjunto de questões indicadas no presente artigo. As abordagens variam. A ênfase, por vezes, pode ser a exposição da dinâmica do poder enquanto controle da vida. Isso fazem com muita propriedade autores como Michel Foucault e Giorgio Agamben. Em outros momentos, a atenção é dedicada à reversibilidade entre os conceitos de biopolítica e tanatopolítica ou necropolítica, isto é, a demonstração de como o controle da vida é também produção de morte. Roberto Esposito e Achille Mbembe tornaramse referências nesta questão. Em outros momentos, tal como podemos observar num conjunto de autores que promovem uma espécie de renascimento da filosofia de Baruch Spinoza, a ênfase é posta no poder da própria vida que resiste, sempre, aos mecanismos de controle. Isso fazem muito bem Gilles Deleuze, Toni Negri, entre outros. No desdobramento destas perspectivas contemporâneas de análise, portanto, entrevemos a atualidade do texto benjaminiano.

Vemos, assim, que a discussão proposta por Walter Benjamin em nenhum momento desconsidera a complexidade das sociedades contemporâneas. A tarefa de uma crítica da violência passa pela compreensão da dinâmica e da constituição histórica da sociedade e de sua legitimação como ordem legal. Além disso, desvenda o poderoso processo de monopolização da violência e sua canalização, única e exclusivamente, para a manutenção da referida ordem. A valorização da vida se dará se esta estiver engajada com a produção e reprodução desta ordem. Quaisquer formas de vida que não estejam empenhadas nisso serão desqualificadas e marginalizadas. (AGAMBEN, 2002). No entanto, a mesma crítica da violência é capaz de mostrar, também, como nenhuma ordem social consegue monopolizar e neutralizar toda e qualquer força, toda potência. O messianismo judaico, uma perspectiva teológica distinta da teologia política oficial, que pretende justificar o poder instituído, aponta para uma realidade, para uma potência divina que nunca pode ser completamente neutralizada. Mesmo no grito de sofrimento da vítima de um sistema violento e brutal, está depositado o inconformismo e a energia de quem não se dobra à ordem instituída.

Argum., Vitória, v. 12, n. 3, p. 58-68, set./dez. 2020. | ISSN 2176-9575 
Dessa maneira, a crítica da violência enquanto crítica simultânea do direito tem ao menos uma dupla função: por um lado, fazer perceber que a violência é algo muito mais enraizado na estrutura social do que se poderia supor num primeiro olhar; por outro lado, mostrar que, apesar de a estrutura social ser permeada pela violência que exerce um controle gigantesco sobre a vida, sempre restam brechas, fraturas, que podem ser "[...] a porta estreita pela qual poderia penetrar o messias" (BENJAMIN, 1994, p. 232; 1991a, p. 704)

\section{Referências}

AGAMBEN, G. Homo sacer: O poder soberano e a vida nua. Tradução Henrique Burigo. Belo Horizonte: Editora UFMG, 2002.

BENJAMIN, Walter. Crítica da Violência - Crítica do Poder. In: BENJAMIN, W. Documentos de Cultura, documentos de barbárie: (escritos escolhidos). Seleção e Apresentação Willi Bolle. Tradução Celeste H.M. Ribeiro de Sousa, et al. São Paulo: Cultrix: Editora da Universidade de São Paulo, 1986.

BENJAMIN, Walter. Sobre o conceito de História. In: BENJAMIN, Walter. Magia e técnica, arte e política: Ensaios sobre literatura e história da cultura. Tradução Sérgio Paulo Rouanet e Prefácio de Jeanne-Marie Gagnebin. São Paulo: Brasiliense, 1994, p. 222-232.

BENJAMIN, Walter. Über den Begriff der Geschichte. In: BENJAMIN, Walter.

Gesammelte Schriften. Band I. (Herausgegeben von Rolf Tiedemann und Hermann Schweppenhäuser). Frankfurt am Main: Suhrkamp, 1991, p. 691-704.

BENJAMIN, Walter. Zur Kritik der Gewalt. In: BENJAMIN, Walter. Gesammelte Schriften. Band II. (Herausgegeben von Rolf Tiedemann und Hermann Schweppenhäuser) Frankfurt am Main: Suhrkamp, 1991b. p. 179-203.

CHAVES, Ernani. Mito e Política: notas sobre o conceito de destino no "jovem" Benjamin. In: Trans/Form/Ação, São Paulo, n. 17, p. 15-30, 1994.

KAFKA, Franz. O processo. Tradução Modesto Carone. Rio de Janeiro: O Globo; São Paulo: Folha de São Paulo, 2003.

LÖWY, Michael. Walter Benjamin: Aviso de Incêndio - uma leitura das teses 'Sobre o Conceito de História'. Tradução Wanda Nogueira C. Brant. São Paulo: Boitempo, 2005.

\footnotetext{
Oneide PERIUS

Doutor em Filosofia pela PUCRS (2011). Realizou estágio pós-doutoral pela mesma Instituição (2016, 2019). É professor Associado no curso de Filosofia da UFT (Universidade Federal do Tocantins, Campus de Palmas) ; no Mestrado Profissional em Prestação Jurisdicional e Direitos Humanos (UFT/ESMAT); no Mestrado Profissional de Filosofia da UFT (PROF-FILO/UFT).
} 